\title{
E1 influjo cervantino en El amor en los tiempos del cólera ${ }^{*}$
}

Fecha de recepción: 25 de abril de 2014

Fecha de aprobación: 2 de septiembre de 2014

\section{Resumen:}

La comparación entre El Quijote de Cervantes y Cien años de soledad de García Márquez ha sido un tema muy recurrente en los estudios garciamarquianos desde la publicación en 1967 de esta última novela. Sin embargo, ha pasado bastante más desapercibida la relación existente entre el clásico de Cervantes y otra gran novela del narrador colombiano: El amor en los tiempos del cólera (1985). Por eso vamos a tratar de realizar ese estudio que venga a llenar, al menos en parte, este vacío crítico respecto al tema, centrándonos sobre todo en dos aspectos: las similitudes entre los personajes de don Quijote y Florentino Ariza en su calidad de locos-cuerdos, y el uso paródico que hacen ambas novelas de los tópicos de dos géneros literarios: los libros de caballería y la literatura amatoria respectivamente.

Palabras clave: Cervantes; García Márquez; intertextualidad; parodia; tópicos literarios.

* Artículo de reflexión perteneciente al proyecto Seis acercamientos comparatistas a la obra de Gabriel García Márquez, que forma parte del Grupo de Investigación en Literatura Comparada.

Citar: Cabello Pino, M. (Enero-junio de 2015). El influjo cervantino en El amor en los tiempos del cólera. La Palabra (26). Páginas 47-58

\section{Manuel Cabello Pino}

Universidad de Huelva, España

manuel.cabello@dfesp.uhu.es

Doctor en Teoría de la Literatura y Literatura Comparada y Profesor de Literatura Española e Hispanoamericana en la Universidad de Huelva (España). 


\title{
la palabra
}

\section{The influence of Cervantes in El amor en los tiempos del cólera [Love in times of cholera]}

\begin{abstract}
:
Comparison between Cervantes' Don Quixote and García Márquez’s Cien años de soledad [One Hundred Years of Solitude] has been a frequent point in studies about García Márquez, since the publication of this last novel in 1967. However, the relationship between Cervantes' classic and the other great novel by García Márquez, Love in the Time of Cholera, has not called so much attention. This is why we set out to make this study, which fulfills this critical lack, at least in partially. In this sense we will focus mainly on two aspects: similarities between the characters of Don Quixote and Florentino Ariza, in their crazy/sane condition, and the parodic use that both novels make of the topics of two literary genres: chivalry books and love literature.
\end{abstract}

Key words: Cervantes; García Márquez; intertextuality; parody; literary topics.

\section{L'influx cervantin dans El amor en los tiempos del cólera [L’amour au temps du choléra]}

\section{Résumé}

La comparaison entre Don Quichotte de Cervantes et Cent ans de solitude de García Márquez a été un sujet très récurrent dans les études garcimarquiennes depuis la publication en 1967 de ce roman-ci. Pourtant, il a passé assez inaperçu le rapport entre le classique de Cervantes et l'autre grand roman du narrateur colombien: L'amour au temps du choléra (1985). C'est pour cela que nous allons essayer de faire cette étude qui vient remplir, au moins en partie, ce vide critique concernant le sujet, en nous centrant surtout sur deux aspects: les similitudes entre les personnages de Don Quichotte et Florentino Ariza dans la qualité de fous-lucides, et l'utilisation parodique qui font les deux romans des sujets de deux genres littéraires : les livres de chevalerie et la littérature amatoire respectivement.

Mots clés: Cervantes, García Márquez, intertextualité, parodie, sujets littéraires. 
Gabriel García Márquez ha sido definido en ocasiones como el mayor "gigante" de las letras hispánicas desde Miguel de Cervantes. Y es que, a casi nadie le ha pasado inadvertido un fenómeno que vincula ineludiblemente a ambos autores: el escritor colombiano ha conseguido desde la publicación en 1967 de su más famosa novela, Cien años de soledad, aunar el favor de crítica y público hasta un nivel tal de fervor que sólo se había dado anteriormente una vez en toda la historia de la literatura escrita en español. Y esa otra ocasión había sido precisamente la aparición en 1605 de la primera parte del Quijote. Este paralelismo tan claro no ha pasado inadvertido a la crítica especializada en la obra de García Márquez, que a pesar de no tenerlo como uno de los principales referentes del premio Nobel colombiano, tal como sí sucede por ejemplo con Faulkner, Hemingway o Sófocles, se ha encargado de relacionar varias de las obras del premio Nobel colombiano con el Quijote. Sin embargo, si hay una novela de García Márquez cuya relación con el Quijote, siendo intensa, ha pasado más desapercibida para la crítica es sin duda El amor en los tiempos del cólera. La relación entre estas dos obras, además de estar mucho menos estudiada que la que se da entre la novela de Cervantes y Cien años de soledad, nos parece mucho más interesante. Con este artículo nos proponemos comenzar a llenar ese vacío crítico, realizando un estudio detallado de varias cuestiones temáticas y estilísticas que vinculan ineludiblemente ambas obras. Pero vamos a empezar por indagar en los orígenes de la relación Cervantes-García Márquez, haciendo además un pequeño repaso del estado de la cuestión.

$\mathrm{Al}$ contrario que otros muchos escritores a los que no les gusta hablar de cuáles son sus autores "de cabecera", a García Márquez siempre le ha gustado explicar cómo fueron sus primeras aproximaciones a los grandes clásicos. En este sentido, el Quijote no es ninguna excepción y, de hecho, en su propia autobiografía, Vivir para contarla, el narrador colombiano explica bien por extenso cómo fueron sus primeros contactos con la famosa novela de Cervantes. Fue uno de sus profesores quien, ya en la escuela primaria, le impulsó a leer la historia del hidalgo manchego. Sin embargo, esa primera tentativa no resultó muy satisfactoria y no sería hasta algunos años más tarde cuando el novelista colombiano aprendiera a degustar la novela cervantina mediante un método ciertamente curioso. García Márquez, haciendo gala de su particular humor caribe, lo cuenta así en su autobiografía:

En cambio, mi lectura del Quijote me mereció siempre un capítulo aparte, porque no me causó la impresión prevista por el maestro $\mathrm{Ca}$ salins. Me aburrían las pe- roratas sabias del caballero andante y no me hacían la menor gracia las burradas del escudero, hasta el extremo de pensar que no era el mismo libro de que tanto se hablaba. Sin embargo, me dije que un maestro tan sabio como el nuestro no podía equivocarse, y me esforcé por tragármelo como un purgante a cucharadas. Hice otras tentativas en el bachillerato, donde tuve que estudiarlo como tarea obligatoria, y lo aborrecí sin remedio, hasta que un amigo me aconsejó que lo pusiera en la repisa del inodoro y tratara de leerlo mientras cumplía con mis deberes cotidianos. Sólo así lo descubrí, como una deflagración, y lo gocé al derecho y al revés hasta recitar de memoria episodios enteros (2002, p. 168)

Parece ser que desde entonces la novela de Cervantes se convirtió en uno de los libros de cabecera del premio Nobel colombiano, hasta tal punto que el Quijote es uno de los temas sobre los que, a lo largo de los años, ha mantenido un diálogo "intenso, constante y vastísimo" con uno de sus más íntimos amigos, el prestigioso escritor mexicano Carlos Fuentes (Eligio García Márquez, 2003, p. 364). Tal vez por eso fuera el propio Carlos Fuentes uno de los primeros en relacionar la obra de García Márquez con el Quijote de Cervantes.

Y es que Cien años de soledad es la novela de García Márquez que con más frecuen- 
cia ha sido comparada con el Quijote, especialmente por dos aspectos: en primer lugar por el recurso de los manuscritos de Melquiades que recuerdan ineludiblemente a los del historiador "moro" Cide Hamete Benengeli del Quijote. Y en segundo lugar, y más importante aún, por constituir Cien años de soledad esa "novela total" a la que aspiraban los autores del Boom, convirtiéndose así en el equivalente latinoamericano del Quijote. Pero también en El otoño del patriarca ${ }^{1}$, en el cuento "El avión de la bella durmiente $^{2 "}$ o en El coronel no tiene quien le escriba ${ }^{3}$ han encontrado los críticos ciertas resonancias cervantinas. $E$ incluso la obra en la que a continuación nos vamos a centrar, El amor en los tiempos del cólera, ha sido previamente relacionada con el Quijote en algunas de las numerosísimas reseñas que acompañaron a la publicación del libro. Tal es el caso de la aparecida en The Economist con el título de "Books and arts. The novel as tropical flower" ${ }^{\prime}$ o la de Tim McCarthy ${ }^{5}$. Sin embargo, en ambos casos la vinculación de la novela de García Márquez con la de Cervantes no pasa apenas de una referencia marginal en el conjunto de la reseña. Un caso distinto es el del estudio de Arnold M. Penuel ${ }^{6}$ en el que también se vincula la novela de García Márquez con la de Cervantes. Pero esa vinculación, aunque desarrollada más extensamente que en las dos reseñas que acabamos de mencionar, se limita a constatar el uso que ambos autores hacen de la conjunción correlativa "No sólo... sino (que) ...", algo que evidentemente no tiene nada que ver con lo que nos proponemos hacer en este estudio.

Y es que la relación de intertextualidad que se establece entre el Quijote y El amor en los tiempos del cólera es mucho más intensa y profunda de lo que la crítica especializada ha sabido ver hasta el momento, y afecta a la novela de García Márquez a nivel literario y no sólo a nivel lingüístico, como sugiere el estudio de Penuel. Por eso vamos a tratar de realizar ese estudio que venga a llenar, al menos en parte, este vacío crítico respecto al tema.
Lo primero que salta a la vista de El amor en los tiempos del cólera, sin pretender si quiera buscar una relación con la novela de Cervantes, es la naturaleza "quijotesca" del personaje de Florentino Ariza. Es decir, el carácter desmesurado de Florentino en relación con todo lo que tenga que ver con el amor (especialmente, la larga espera por el amor de su vida, Fermina Daza) recuerda claramente a la naturaleza desorbitada de don Quijote en todo lo tocante a la caballería. Pero esto por sí sólo, más que una relación de hecho, no deja de ser en realidad una simple sensación que percibe el lector. Sin embargo, si realizamos una lectura más atenta podemos comprobar cómo la conexión "quijotesca" de Florentino no acaba ahí. En primer lugar, ambos personajes constituyen hasta cierto punto sendas sátiras o parodias de otros personajes-tipo de ficción. Y es que, si el personaje de don Quijote se basa en una parodia de los caballeros andantes de los libros de caballería, tales como Amadís de Gaula, Palmerín, Tirante el Blanco... etc., Florentino Ariza se basa

1 Véase Ciro Antonio Camargo Rojas y Victorino Polo García, "Gabriel García Márquez: Literatura y mito. "El otoño del Patriarca" a la sombra de Cervantes", Anales de la Universidad de Murcia, Murcia, XLIII, 1984-85, p. 79-110.

2 Véase Brett Weaver, "Gabriel García Márquez Attends the Courtly Love Convention", Notes on Contemporary Literature (NconL), 29: 4, (1999 Sept), 10-12.

3 Véase Michael Bell (1993). Gabriel García Márquez. Solitude and solidarity. London: The MacMillan Press: 25-27.

4 "Books and Arts: The Novel as Tropical Flower", The Economist (London, England), July 2, 1988, 308 (7557), pp. 77-78.

5 Tim McCarthy, "Love and Cholera Under a Yellow Flower Rain: Gabriel García Márquez and the Legacy of Don Quixote", National Catholic Reporter, (May 12, 1989) 25 (29), pp. 21-23.

6 Arnold M. Penuel, Intertextuality in García Márquez, York, South Carolina, Spanish Literature Publications, 1994. 
en una sátira, una exageración de personajes propios de las novelas más románticas como el Frédéric Moreau de L'Éducation sentimentale o el Werther de la obra homónima de Goethe. Ambos son, por lo tanto, en cierto sentido personajes metaliterarios. Pero es que, además, el carácter de sátira de sendos personajes-tipo ("caballero andante" y "héroe romántico") tiene en don Quijote y en Florentino Ariza la misma causa: si el primero pierde el juicio por su afición desmesurada a la lectura de las novelas de caballería, el segundo está totalmente influido en su carácter y en su comportamiento por las lecturas a las que es aficionado, que son todas de tipo amatorio. Al igual que le ocurre a don Quijote, a Florentino Ariza la lectura se le convierte en un vicio:

La lectura se le convirtió en un vicio insaciable. Desde que lo enseñó a leer, su madre le compraba los libros ilustrados de los autores nórdicos, que se vendían como cuentos para niños, pero que en realidad eran los más crueles y perversos que podían leerse a cualquier edad. Florentino Ariza los recitaba de memoria a los cinco años, tanto en las clases como en las veladas de la escuela, pero la familiaridad con ellos no le alivió el terror. $\mathrm{Al}$ contrario, lo agudizaba. De allí que el paso a la poesía fue como un remanso. Ya en la pubertad había consumido por orden de aparición todos los volúmenes de la Biblioteca popular que Tránsito Ariza les compraba a los libreros de lance del Portal de los Escribanos, y en los que había de todo, desde Homero hasta el menos meritorio de los poetas locales. Pero él no hacía distinción: leía el volumen que llegara, como una orden de la fatalidad, y no le alcanzaron todos sus años de lecturas para saber qué era bueno y qué no lo era en lo mucho que había leído. Lo único que tenía claro era que entre la prosa y los versos prefería los versos, y entre éstos prefería los de amor, que aprendía de memoria aun sin proponérselo desde la segunda lectura, con tanta más facilidad cuanto mejor rimados, y cuanto más desgarradores ${ }^{7}$.

Y ese hábito de la lectura compartido por sendos personajes acaba teniendo en ambos el mismo efecto nocivo. En palabras de Antonio Barnés:

Las lecturas no solo han configurado la personalidad de Don Quijote, sino que también le han otorgado una visión y una misión en el mundo. Porque, no lo olvidemos, don Quijote ha leído toda clase de libros, pero el género caballeresco ha sido el que le ha producido una fascinación más intensa y el que le ha impulsado a vivir la vida de sus personajes (2012, p. 60).
Por su parte, también Florentino, al igual que le sucedía a Alonso Quijano, acaba comportándose como los personajes de las obras que tanto le gusta leer, y por lo tanto, acaba convirtiéndose en uno de ellos, de modo que en $E l$ amor en los tiempos del cólera, al igual que pasaba en el Quijote, la realidad escrita acaba contaminando a la realidad real. Si don Quijote se cree un personaje de novela de caballería y como tal se comporta, Florentino se "cree" un personaje de novela de amor $y$, por lo tanto, también se comporta como tal. El siguiente pasaje resulta tremendamente revelador respecto a esta actitud:

De noche, cuando amarraban el buque y la mayoría de los pasajeros caminaban sin consuelo por las cubiertas, él repasaba casi de memoria los folletines ilustrados bajo la lámpara de carburo del comedor, que era la única encendida hasta el amanecer, y los dramas tantas veces releídos recobraban su magia original cuando él sustituía a los protagonistas imaginarios por conocidos suyos de la vida real, y se reservaba para sí y para Fermina Daza los papeles de amores imposibles (p. 205).

$\mathrm{Y}$ es que, igual que Don Quijote, Florentino también considera más bonito y más interesante el mundo de las novelas que lee que aquel en el

$7 \quad$ Para las citas de El amor en los tiempos del cólera se seguirá la edición de Plaza y Janés Editores, S.A., 1997. 
que le ha tocado vivir. Si a don Quijote le parecen dignas de admiración las hazañas de los caballeros andantes y por eso los imita, a Florentino lo que le parece digno de admiración son los enamorados de las novelas de amor (caracterizados por la desmesura) de ahí que él intente imitarlos para ganarse el favor de su dama. Buenos ejemplos de esta actitud de Florentino son las cartas de amor pasional que escribe a Fermina así como los regalos que le hace, la determinación de tocar por la noche bajo su balcón el valse que compuso para ella, el enfrentarse al padre, Lorenzo Daza, que amenaza con pegarle un tiro, diciéndole "Péguemelo -dijo, con la mano en el pecho-. No hay mayor gloria que morir por amor." (p. 122), el intento de rescatar el tesoro del galeón hundido, y sobre todo, su determinación de respetar "a su manera" su juramento de fidelidad eterna y amor para siempre hacia Fermina durante más de cincuenta años a pesar de haber sido abandonado por ella.

Todo esto nos lleva a otro paralelismo entre ambas obras: y es que, en definitiva, la parodia en la novela de García Márquez surge, al igual que en la novela de Cervantes, del choque de colocar un "personaje de novela" en el mundo real. En el caso del Quijote lo ha explicado muy bien Vargas Llosa, según el cual a Don Quijote:

(...) Lo anima un designio enloquecido: resucitar el tiempo eclipsado siglos atrás (y que, por lo demás, nunca existió) de los caballeros andantes, que recorrían el mundo socorriendo a los débiles, desfaciendo tuertos $y$ haciendo reinar una justicia para los seres del común que de otro modo jamás alcanzarían, del que se ha impregnado leyendo las novelas de caballerías, a las que él atribuye la veracidad de escrupulosos libros de historia. Este ideal es imposible de alcanzar porque todo en la realidad en la que vive el Quijote lo desmiente: ya no hay caballeros andantes, ya nadie profesa las ideas ni respeta los valores que movían a aquellos, ni la guerra es ya un asunto de desafíos individuales en los que, ceñidos a un puntilloso ritual, dos caballeros dirimen fuerzas (...)

(...) La literatura caballeresca que hace perder los sesos al Quijote -ésta es una expresión que hay que tomar en un sentido metafórico más que literal- no es "realista", porque las delirantes proezas de sus paladines no reflejan una realidad vivida (...)

(...) Así, el sueño que convierte a Alonso Quijano en don Quijote de la Mancha no consiste en reactualizar el pasado, sino en algo todavía mucho más ambicioso: realizar el mito, transformar la ficción en historia viva. (2004, pp. 13-14)

Lo mismo le ocurre a Florentino: él quiere llevar a la práctica de su relación amatoria con Fermina las cosas que ha leído en los folletines de lágrimas que tanto le gustan, quiere actuar como actúan los héroes románticos de esas novelas. Pero el problema es que esa literatura, al igual que la caballeresca, tampoco es "realista", porque tampoco las "proezas" de los héroes románticos "reflejan una realidad vivida". De modo que, también el sueño de Florentino consiste en "transformar la ficción en historia viva". Y es el choque de la ficción al ser insertada en la vida real el que provoca la parodia, rozando a veces el esperpento. En el caso de la novela de Cervantes, tal como ha dicho Francisco Ayala, "Desde las primeras páginas del Quijote, el hidalgo trastornado choca, en su quimera caballeresca, con la realidad ambiente; una realidad vulgar, hecha de circunstancias humildes, casi naturales en su elementalidad, tradicionales en todo caso (...)" (2004, p. 38). En El amor en los tiempos del cólera la quimera romántica de Florentino también choca con la realidad que le rodea. Y, sobre todo, choca frontalmente con el carácter realista y mesurado de su amada Fermina Daza. Como ésta es una mujer que no vive como él en el mundo ficticio de los folletines de lágrimas, sino que tiene su cabeza bien asentada en el mundo real no puede apreciar lo que él hace. Más bien al contrario, cuando son jóvenes las "hazañas" de Florentino le parecen locuras, pero cuando son ancianos simplemente le parecen ridículas, auténticas chiquilladas. Pero es que la desmesura de la concep- 
ción del amor del personaje de Florentino Ariza choca incluso con las expectativas de los lectores que se acercan a la novela de García Márquez, hasta tal punto que no resulta extraño que en una ocasión, en un programa radiofónico, se diese esta conversación entre un lector de la novela y el propio escritor colombiano:

- ¿(...) usted cree que todo el amor que describe en su último libro puede ser real, puede darse en la realidad? -Creo que sí es real y por eso lo utilizo en la novela, si no, no lo hubiera utilizado, porque a pesar de mi fama de realista mágico o de realista fantástico, la verdad es que yo soy un realista de la realidad (1989, p. 42).

Y es que a García Márquez le sucede con El amor en los tiempos del cólera lo mismo que a Cervantes con el Quijote: ellos sí son escritores realistas, lo que no son realistas son el tipo de lecturas que gustan a sus dos personajes (Don Quijote y Florentino Ariza), que son las que condicionan el comportamiento y la personalidad de los mismos, alterándolos.

Y al hilo de esto, todavía hay otro elemento en común entre don Quijote y Florentino Ariza a la hora de provocar la sátira y la parodia: y es que, al vivir ambos en sus respectivos mundos de fantasía, el resto de la gente con la que tienen que tratar se da cuenta rápidamente de su inocencia y acaba por aprovecharse de ellos. En el Quijote se ve muy claramente, por ejemplo, en la aventura de los galeotes, en la que el hidalgo libera a un grupo de delincuentes que unos alguaciles llevan a cumplir su condena en las galeras del rey. Don Quijote, alterada su percepción por los libros de caballería, cree estar liberando de la tiranía a unas personas inocentes, algo que evidentemente dista mucho de la realidad. Al final los galeotes, liderados por el bandolero Ginés de Pasamonte, acaban "agradeciéndole" el favor a Don Quijote apedreando y robando a éste y al pobre Sancho. En el caso de El amor en los tiempos del cólera el episodio en el que más claramente se percibe esto mismo es aquel en el que Florentino tiene noticia de la historia de un viejo galeón español hundido en las costas de su ciudad e, influido por lo que ha leído en sus novelas románticas, concibe el descabellado plan de tratar de rescatarlo por sus propios medios para su amada Fermina. Por supuesto, en cuanto pide ayuda a un niño buceador, Euclides, éste mucho más anclado en la realidad que el propio Florentino, se da cuenta de la inocencia de éste y le toma el pelo tranquilamente durante algún tiempo hasta que, al final alguien le abre los ojos a Florentino y el niño desaparece.

Pero si hay un aspecto de la personalidad que vincula a don Quijote y a Florentino Ariza esa es la condición de lococuerdo $^{8}$ que ambos comparten. Es decir, a pesar de que, como hemos venido explicando, ambos viven en su mundo de fantasía (don Quijote en el de los libros de caballería y Florentino en el de los folletines de lágrimas) lo que les hace ser vistos por los demás personajes como auténticos locos, sorprendentemente conservan la cordura respecto a todo lo que no sea la caballería o el amor respectivamente. A lo largo de la novela de Cervantes se hacen alusiones constantes a dicha condición de Don Quijote. Primero por lo que opinan los otros personajes de él y segundo por lo que la desmesura de sus propias acciones en contraste con sus admirables opiniones en otros aspectos nos muestra a los lectores de la obra. Y es que, algunos personajes hacen especial hincapié en el hecho de que Don Quijote sólo desvaría cuando trata de la caballería, mientras que sus discursos, opiniones y consejos respecto a cualquier otro tema son dignos de la más profunda admiración. Sancho, por ejemplo, queda a veces "admirado de sus hechos como

8 Sobre la condición de loco-cuerdo de Don quijote véase Gallardo Saborido, Emilio José, "Entre burlas y veras: Don Quijote como loco-cuerdo", Espéculo. Revista de estudios literarios, 2009, n 41. 
de sus dichos: porque andaban mezcladas sus palabras y sus acciones, con asomos discretos y tontos". Lo mismo le ocurre a Florentino Ariza a lo largo de El amor en los tiempos del cólera, sólo que, dado el secretismo de su comportamiento, sólo Fermina Daza y nosotros como lectores somos conscientes de su condición de loco-cuerdo. Así vemos cómo el narrador llama loco a Florentino en numerosas ocasiones a lo largo de la novela. Como cuando se dice que Fermina "Se habría creído frente a un loco si no hubiera tenido motivos para pensar que Florentino Ariza estaba en aquel instante inspirado por la gracia del Espíritu Santo.” (p. 77), o cuando se dice que ésta misma “(...) cuando siguió recibiendo otras cartas con pormenores todavía más fantásticos, y escritos con tanta seriedad como sus promesas de amor, tuvo que confesarle a Hildebranda su temor de que el novio alucinado hubiera perdido el juicio" (p. 139), o cuando sus cartas de amor de juventud son definidas como "lunáticas" (p. 104). Sin embargo, al igual que ocurre con Don Quijote, su locura se limita sólo a lo relacionado con el amor, y se torna sabiduría digna de admiración cuando habla de otros temas. Por eso cuando ya en la vejez Florentino envía a Fer- mina unas cartas llenas de reflexiones sobre la vida se dice que a Fermina "De ese modo se le revelaba un Florentino Ariza desconocido, con una clarividencia que no correspondía a las esquelas febriles de juventud ni a su conducta sombría de toda la vida" (p. 424) y que "No entendía cómo un hombre capaz de hacer las reflexiones que tanto apoyo le habían dado para sobrellevar la viudez, se enredaba de aquel modo infantil cuando trataba de aplicarlas a su propia vida" (p. 447).

Ya hemos mencionado anteriormente que el personaje de don Quijote se basa en una parodia de los caballeros andantes de las novelas de caballería, mientras que Florentino Ariza lo hace en una exageración de los héroes de las novelas románticas, los llamados folletines de lágrimas. Pero ¿cómo construyen Cervantes y García Márquez sus respectivas parodias? ¿qué hacen para lograr el tono humorístico que impregna ambas novelas? Pues ambos utilizan la misma técnica: recurrir en sus respectivas novelas a una serie de tópicos literarios ${ }^{9}$ bien conocidos por los lectores, precisamente para sorprender las expectativas de estos mediante giros humorísticos inesperados de dichos tópicos. Se podría decir que am- bos recurren a los tópicos literarios, pero utilizando siempre la técnica clásica de la imitatio cum variatione. Es decir, repiten los elementos constitutivos propios de cada tópico que ya estaban en la tradición, pero llevándolos siempre un paso más allá, en sus casos a través del humor y la exageración. El humor es precisamente esa variatio, ese elemento original que aportan a la tradición del tópico. La única diferencia está en que el primero recurre a los tópicos de las novelas de caballerías, mientras que el segundo utiliza los tópicos amatorios clásicos.

En el Quijote, un primer ejemplo lo tenemos en el capítulo XI de la segunda parte, titulado De la extraña aventura que le sucedió al valeroso don Quijote con el carro o carreta de "Las Cortes de la Muerte", que supone una parodia nada disimulada de un tópico que se inicia precisamente con una de las novelas fundadoras del género de las novelas de caballería: El caballero de la carreta de Chrétien de Troyes. Otro claro ejemplo lo constituye el capítulo XVIII de la segunda parte, titulado De lo que sucedió a don Quijote en el castillo o casa del Caballero del Verde Gabán, con otras cosas extravagantes, que desde el propio título alude ya claramente a otra de las obras

9 Sobre el concepto de tópico literario véanse Miguel Ángel Márquez Guerrero, "Tema, motivo y tópico. Una propuesta terminológica”, Exemplaria 6, 2002, 251-256 y Maria Isabel López Martínez, El tópico literario: teoría y crítica, Madrid, Arco/Libros, S.L., 2007. 
más conocidas del ciclo artúrico: Sir Gawain and the Green Knight, poema de la literatura inglesa del siglo XIV. Lo mismo sucede con los capítulos XXII Donde se da cuenta de la grande aventura de la cueva de Montesinos, que está en el corazón de la Mancha, a quien dio felice cima el valeroso don Quijote de la Mancha, XXIII De las admirables cosas que el extremado don Quijote contó que había visto en la profunda cueva de Montesinos, cuya imposibilidad y grandeza bace que se tenga esta aventura por apócrifa y XXIV Donde se cuentan mil zarandajas tan impertinentes como necesarias al verdadero entendimiento de esta grande historia, todos ellos de la segunda parte. A lo largo de estos tres capítulos Cervantes lleva a cabo una clara parodia del tópico de la catábasis, el descensus ad inferos que se remonta a la Odisea, y se vuelve luego lugar común en las novelas de caballería. Otros tópicos parodiados por Cervantes son, el enfrentamiento con criaturas mitológicas o fantásticas como gigantes, los encantamientos que sufren los caballeros por parte de los hechiceros enemigos, la edad de oro o aurea aetas, la aventura de los leones, las penitencias impuestas a los caballeros por sus damas o el diálogo entre los escuderos, por citar sólo algunos.
Por su parte, García Márquez en El amor en los tiempos del cólera parodia tópicos como, por ejemplo, el de la enfermedad de amor, al asociar durante toda la novela (ya desde el propio título) los síntomas que provoca el amor con los de otra enfermedad tan "poco romántica" como es el cólera, que presenta síntomas como los vómitos verdes o el estreñimiento. Otros tópicos amatorios parodiados por García Márquez son los de la fides, la fidelidad entre los amantes, y el foedus amoris, el pacto de amor. Y es que, García Márquez hace a su héroe romántico, Florentino Ariza, respetar su pacto de amor con Fermina Daza, y mantenerse fiel a ella (aunque con una concepción de la fidelidad ciertamente peculiar y más que discutible) durante más de cincuenta años, a pesar de que ella esté durante esos cincuenta años casada con otro y sin mantener ningún tipo de contacto con él. Y en el caso de El amor en los tiempos del cólera la lista sigue con otros tópicos como la erotodidaxis, la esclavitud del amor, la caza del amor, la guerra del amor o militia amoris, el triángulo amatorio elegíaco, las señales secretas en el amor prohibido, el amor secreto o furtivus amor, el amante rechazado a la puerta de la amada o paraklausithyron $\mathrm{O}$ exclusus amador o la amada como diosa o puella divina ${ }^{10}$.
Del Quijote se ha dicho muchas veces que su propósito es la crítica de los libros de caballería. Pero, sin negar este propósito (que a veces ha sido discutido), la novela de Cervantes es mucho más que eso. Mientras lleva a cabo esa crítica de los libros de caballería consigue ser además en palabras de Gallardo Saborido (Gallardo Saborido, 2009, p. 2) “(...) una reflexión apasionada y mordaz sobre los más variados aspectos (culturales, sociales, políticos, religiosos, etc.)". Lo mismo ocurre con $E l$ amor en los tiempos del cólera. En ella, mientras lleva a cabo una sátira de los folletines de lágrimas del s. XIX, García Márquez consigue además realizar una novela que trasciende este mero propósito para convertirse en una intensa reflexión sobre diversos aspectos (también culturales, sociales, políticos y religiosos) pero especialmente sobre el amor en todas sus variantes. Y es que, si Cervantes, según opina Vargas Llosa, más que intentar ridiculizar las novelas de caballería lo que hizo fue rendirles:

\footnotetext{
(...) un soberbio homenaje y una de sus grandes proezas literarias consistió en actualizarlo, rescatando de él, mediante el juego y el humor, todo lo que en la narrativa caballeresca podía sobrevivir y aclimatarse a
}

10 Para un estudio más detallado del tratamiento que hace García Márquez de estos tópicos amatorios clásicos en su novela véase Manuel Cabello Pino, Motivos y tópicos amatorios clásicos en El amor en los tiempos del cólera. Huelva: Servicio de Publicaciones de la Universidad de Huelva, 2010. 
los valores sociales y artísticos de una época, el siglo XVII, muy distinta de aquella en la que había nacido. (2004, p. 22)

García Márquez, hace lo mismo pero con las novelas románticas y los folletines de lágrimas del siglo XIX. Es decir, el novelista colombiano, a pesar de utilizar la parodia $y$ el humor, no quiere ridiculizar dicho género. Todo lo contrario, él ha declarado muchas veces ser un romántico empedernido y un gran admirador de los folletines de lágrimas, $\mathrm{y}$ con la utilización de los tópicos propios de dicho género (al igual que Cervantes con los de las novelas de caballería) demuestra sentir un gran respeto por él. Y es que, tal como ha dicho Claudio Guillén a propósito de la utilización de los tópicos literarios:

Las reiteraciones no suelen ser estáticas. Quien cita, valora lo repetido -no calcando sino recalcando-; o bien manifiesta, con tenacidad que llega a ser patética, una voluntad de continuidad. Entonces el topos interesa no como realidad textual, acaso banal y socorrida, sino como signo; es decir, como reconocimiento de un conjunto cultural, de una longue durée, con la que el escritor enlaza activamente y se declara solidario. (Gui-

llén, 1985, p. 276)

Por lo tanto, lo que García Márquez pretende con El amor en los tiempos del cólera es rendirle un homenaje a dicho género, rescatando de él todo lo que aún hoy es aprovechable, y haciendo lo necesario para adaptarlo a los valores sociales y artísticos de una época, la actual, muy distinta a la que vio nacer el género en el siglo XIX. ¿Y cómo lo hace? Pues también igual que Cervantes, de la única manera que podía resultar realmente eficaz, utilizando el juego, el humor, la sátira y la parodia, para inyectarle nueva vida a géneros que de otro modo parecerían ya desfasados.

En definitiva, ambos novelistas siguen un modelo paródico común, de modo que la principal técnica que García Márquez parece heredar de Cervantes en El amor en los tiempos del cólera es la aplicación del humor a una historia que, en principio, parece ser mucho más seria y profunda. Según Martín de Riquer:

(...) no hay que olvidar que el Quijote, a pesar de su profundidad y de la amargura que parece encerrar -amargura a la que está más pre- dispuesto el lector actual que el de principios del siglo XVII- es, como diríamos hoy, un libro "humorístico". En la fórmula antes transcrita ya se advierte que uno de los propósitos del escritor es divertir a sus lectores: "que el melancólico se mueva a risa, el risueño la acreciente". Quien no ríe leyendo el Quijote es o porque no entiende la novela o porque tiene la desgracia de no poseer la facultad de reír (...) $(2004$, p. 73$)$

Lo mismo ocurre con la novela de García Márquez. Ésta es, sin lugar a dudas, una bella historia de amor, en el fondo llena de amargura porque tiene que esperar toda una vida para realizarse, y ninguno de los dos protagonistas es realmente feliz hasta el final de sus vidas. Sin embargo, la manera que tiene García Márquez de llevarnos por esa historia está totalmente dominada por el humor. Su propósito como el de Cervantes es contar una historia profunda $y$, en realidad, amarga, pero divirtiendo a sus lectores por el camino, de modo que quien no ríe leyendo El amor en los tiempos del cólera es también "o porque no entiende la novela o porque tiene la desgracia de no poseer la facultad de reír". 


\section{Referencias}

(1989). Alooo...Gabo: Gabriel García Márquez responde en directo a sus lectores. Paris, France, Centre Culture Colombia, Bogotá, Colombia: Ediciones David \& Ayala.

Ayala, F. (2004). La invención del “Quijote”. En: Miguel de Cervantes, Don Quijote de la Mancha (pp. 2943). ed. Francisco Rico, Real Academia Española, Asociación de Academias de la Lengua Española. Madrid: Santillana Ediciones Generales, S. L.

Barnés Vázquez, A. (2012). Lecturas de locura, lecturas de cordura. Anuario de Estudios Cervantinos, VIII, 57-69.

Bell, M. (1993). Gabriel García Márquez. Solitude and solidarity. London: The MacMillan Press.

(July 2, 1988). Books and Arts: The Novel as Tropical Flower. The Economist (London, England), 308 (7557), 77-78.

Cabello Pino, M. (2010). Motivos y tópicos amatorios clásicos en El amor en los tiempos del cólera. Huelva: Servicio de Publicaciones de la Universidad de Huelva.

Cervantes, M. de (2004). Don Quijote de la Mancha. Ed. Francisco Rico. Real Academia Española, Asociación de Academias de la Lengua Española. Madrid: Santillana Ediciones Generales, S. L.

Fuentes, C. (2002). La nueva novela hispanoamericana. México: Planeta DeAgostini.

Gallardo Saborido, E. J. (2009). Entre burlas y veras: Don Quijote como loco-cuerdo. Espéculo. Revista de estudios literarios, $\mathrm{n}^{\circ}$ 41. Recuperado de http://pendientedemigracion.ucm.es/info/especulo/numero41/ burlasqu.html

García Márquez, E. (2001). Tras las claves de Melquíades. Barcelona: Mondadori.

García Márquez, G. (2002). Vivir para contarla. Barcelona: Mondadori.

García Márquez, G. (1997). El amor en los tiempos del cólera. Barcelona: Plaza y Janés Editores S.A.

Guillén, C. (1985). Entre lo uno y lo diverso. Introducción a la literatura comparada. Barcelona: Crítica.

López Martínez, M. I. (2007). El tópico literario: teoría y crítica. Madrid: Arco/Libros, S.L.

Márquez Guerrero, M. Á (2002). Tema, motivo y tópico. Una propuesta terminológica. Exemplaria, 6, 251 256.

McCarthy, T. (1989) Love and Cholera Under a Yellow Flower Rain: Gabriel García Márquez and the Legacy of Don Quixote. National Catholic Reporter, 25 (29), 21-23.

Penuel, A. M. (1994). Intertextuality in García Márquez. York, South Carolina: Spanish Literature Publications. 
Riquer, Martín de, Cervantes y el “Quijote”. En: Miguel de Cervantes, Don Quijote de la Mancha (pp. 45-75). ed. Francisco Rico, Real Academia Española, Asociación de Academias de la Lengua Española. Madrid: Santillana Ediciones Generales, S. L.

Swanson, P. (1991). Cómo leer a Gabriel García Márquez. Madrid: Ediciones Júcar.

Vargas Llosa, M. (2004). Una novela para el siglo XXI. En: Miguel de Cervantes, Don Quijote de la Mancha (pp. 13-28). ed. Francisco Rico, Real Academia Española, Asociación de Academias de la Lengua Española. Madrid: Santillana Ediciones Generales, S. L. 